\title{
Attitudes of Students toward Inter Professional Healthcare Teams: A Comparison between 1st-Year and 3rd-Year Students at Mongolian National University of Medical Sciences
}

\begin{abstract}
Azjargal Baatar ${ }^{1 *}$, Takatoshi Makino ${ }^{2,3}$, Sumberzul Nyamjavi ${ }^{1}$, Oyuntsetseg Sandag ${ }^{1}$, BatgerelOidov ${ }^{4}$, Basbish $^{2}$ Tsogbadrakh², Enkhchimeg Khuyagbaatar ${ }^{2}$, Bumsuk Lee $^{2,3}$, Hiroki Matsui ${ }^{2,3}$, Yoshiharu Tokita ${ }^{2,3}$, Hiromitsu Shinozaki ${ }^{2,3}$, Akinori Kama ${ }^{3,5}$, Masaaki Sakamoto², Rie Nakazawa² and Hideomi Watanabe ${ }^{2,3}$
\end{abstract}

${ }^{1}$ Mongolian National University of Medical Sciences, Mongolia

${ }^{2}$ Graduate School of Health Sciences, Gunma University, Japan

${ }^{3}$ WHO Collaborating Centre for Research and Training on Inter professional Education, Gunma University, Japan

${ }^{4}$ The 3 rd Hospital, Mongolia

${ }^{5}$ Gunma University Initiative for Advanced Research, Japan

Submission: August 16, 2018; Published: November 02, 2018

*Corresponding author: Azjargal Baatar, Mongolian National University of Medical Sciences, Bayangol district, 6th khoroo, Ard Ayush street, P.O.Box-188, Ulaanbaatar-26, Mongolia

\footnotetext{
Abstract

Objective

The purpose of this study is to describe attitudes toward inter professional education in Mongolia National University of Medical Sciences. Methods

Cross-sectional study, Heinemann et al. [1] developed the Attitudes Toward Health Care Teams Scale (ATHCTS, 21-item instrument), which has potential for evaluating clinically based team training programs as well as use a pre- and post-test tool for educational interventions with teams. A 14-item instrument in which items containing the word "physician" have been removed from the original instrument is a modified version adapted by Curran et al. [2] to measure attitudes towards health care teams.

Results

In total, 249 I grade and 243 III grade undergraduate students participated in the study, respectively. Response rates by academic units of the undergraduate students were NS 88.3\% ( $\mathrm{n}=223)$, MD 39.0\% ( $\mathrm{n}=193)$, PT 53.8\% ( $\mathrm{n}=29), \mathrm{LS} 42.0 \%(\mathrm{n}=47)$, respectively. As shown in Table 1, comparisons using the Mann-Whitney test indicated that in mean scores of seven items, item $1(3.83 \pm 1.169$ vs $4.38 \pm 0.854, P<0.0001)$, item 3 ( $3.97 \pm 1.167$ vs $4.43 \pm 0.702, \mathrm{p}<0.05)$, item $4(3.99 \pm 1.163$ vs $4.61 \pm 0.62, \mathrm{P}<0.0001)$, item $13(3.5 \pm 1.164$ vs $4.11 \pm 0.946, \mathrm{P}<0.001), 1^{\text {st }}$ year students showed significantly lower scores than $3^{\text {rd }}$ year undergraduate students.

Conclusion

The present results showed that students possessed more positive attitudes toward IPE than I years undergraduate students, suggesting that exposure to clinical practice may result in withdrawal of the attitudes toward healthcare teams.

Keywords: Inter professional education; Team value; Team efficiency

Abbreviations: WHO: World Health Organization; IPE: InterProfessional Education; MNUMS: Mongolian National University of Medical Sciences;
} ATHCTS: Attitudes Toward Health Care Teams Scale

\section{Introduction}

Mongolia is a landlocked country in East Asia, bordered by China and Russian Federatio. Its population was estimated to be around 3,100,058.(www.1212.mn) Mongolian National University of Medical Sciences is located in Ulan Bator, the capital sity, and consists of five schools and three colleges; School of Medicine (doctors), School of Public, School of Pharmacy and Biomedical Sciences (Lab technicians), School of Dentistry, School of Nursing. The School of Nursing consists of five health professionals nurses, 
midwives, physical therapists, occupational therapists, technician of medical equipment. The MNUMS offers training of five different qualifications of health professionals such as nurses, doctors, physical therapists, occupational therapists, lab technician. It is the sole health professionals national university (MNUMS) in the country. It was realised that MNUMS has not been providing IPE program. However the graduate school of health sciences at Gunma University partnered with the MNUMS and and entered into a faculty exchange agreement in July 2007, to support the establishment of a department of physical therapy and to promote the role and education of physical therapists [2].

Patients have complex health needs and typically require more than one discipline to address issues regarding their health status [3]. The Institute of Medicine Committee on Quality of Health Care in America recommended that healthcare professionals who work in interprofessional teams can communicate and address these complex and challenge [4]. World Health Organization (WHO)recommend health professionals' education and training institutions should consider implemeting Interprofessional education (IPE) in both undergraduate and postgraduate programmes [5]. Previous study reported the current curriculum to find the possibility of integrating the different health professional programmes into the IPE initiative [6,7]. IPE is an approach to develop healthcare students for future interprofessional teams [8]. The purpose of this study was to investigate attitudes of students toward interprofessional education at MNUMS before providing IPE program.

\section{Methods}

\section{Study design}

The present cross-sectional study was a descriptive investigation designed to test the effects of curriculum on students' attitudes toward health care teams by comparing the attitudes between 1st-year and 3rd-year students at Mongolian National University of Medical Sciences (MNUMS) which delivers curricula without an IPE program.

\section{Study population}

The MNUMS consists of the departments of Nursing (129 and 53 first- and third-year students, respectively), Physical Therapy (35 and 26 students), Occupational Therapy (10 and 0 students), and Medical Doctor (500 and 493 students). The present study was performed in the 2015 academic year, and thus the first-year students were a different population from the third-year students.

\section{Survey instrument}

Heinemann et al. [1] developed the Attitudes Toward Health Care Teams Scale (ATHCTS, 21-item instrument), which has the potential for evaluating clinically-based team training programs and can be used as a pre- and post-test tool for educational interventions with teams. A modified 14-item instrument that removed items containing the word "physician" from the original instrument was created by Curran et al. [2] to measure attitudes toward health care teams. We used this 14-item instrument in our survey to measure students' attitudes toward health care teams. Responses were provided on a five-point Likert scale from one (strongly disagree) to five (strongly agree), in accordance with Curran et al. [2]. The modified ATHCTS has not yet been fully analyzed for reliability and validity in measuring attitudes toward health care teams, although a high rate of internal consistency (Cronbach's alpha of 0.773 ) with a clear factor solution with three subscales was obtained in our previous examination $[10,11]$. Negatively worded items were reverse-scored. A high score indicates a positive attitude toward health care teams.

\section{Study procedure}

This study was conducted in 2015. During the first term, an attitudinal survey was administered to the students and supervised by the professors responsible for each class. Survey responses were always confidential and names and other identifying information were removed.

\section{Statistical analysis}

Data combined from 1st- and 3rd-year students at MNUMS were analyzed using the Statistical Package for the Social Sciences, version 22.0J. The scale was subjected to exploratory factor analysis to examine the underlying constructs of the survey. The suitability of the correlation matrix was determined by the KaiserMeyer-Olkin estimate of sampling adequacy and Bartlett's Test of Sphericity. The number of factors retained for the initial solutions and entered into the rotations was determined with application of Kaiser's criterion (eigenvalues $>1$ ). The initial factor extractions were performed by means of principal component analysis. To clearly define the structure, an exploratory factor analysis using varimax rotation was conducted. To determine how the resultant factors influenced the difference between students at MNUMS, regression factor scores were obtained for the scale used in the present study DiStefano, et al. [12]. Since the data were not normally distributed according to the Shapiro-Wilk test, the Mann-Whitney U test was used to analyze independent variables. The level of significance was set at $5 \%$ for all tests.

\section{Ethics}

This study was approved by the Epidemiologic Research Ethics Committee of MNUMS (MNUMS, Ulaanbaatar, Mongolia).

\section{Results}

\section{Demographics of respondents}

One hundred and ninety eight respondents of a possible 1246 completed the survey for a total response rate of $15.9 \%$, for firstand third-year students 99 and 99 completed the survey, with response rates of $14.7 \%$ and $17.3 \%$, respectively (Table 1 ).

\section{Overall modified ATHCTS mean score}

As shown in Table II, the overall modified ATHCTS mean score of 3rd-year students at MNUMS was significantly higher than that of 1 st-year students at MNUMS (3.970 \pm 1.101 vs. $3.610 \pm 1.246$, $\mathrm{p}<0.001$ ) (Tables 2). 
Table 1: Responding sample demographics.

\begin{tabular}{|c|c|c|c|c|c|c|c|c|}
\hline & \multicolumn{4}{|c|}{ 1st -year students } & \multicolumn{3}{|c|}{ 3rd-year students } & \multirow[b]{2}{*}{ Response Rate } \\
\hline & Object Person & Responses & Valid Response & Response Rate & Object Person & Responses & Valid Response & \\
\hline NS & 129 & 77 & 67 & $51.90 \%$ & 53 & 46 & 38 & $71.70 \%$ \\
\hline PT & 35 & 27 & 19 & $54.30 \%$ & 26 & 20 & 13 & $50.00 \%$ \\
\hline OT & 10 & 10 & 9 & $90.00 \%$ & - & - & - & - \\
\hline MD & 500 & 4 & 4 & $0.80 \%$ & 493 & 53 & 48 & $9.70 \%$ \\
\hline Total & 174 & 114 & 95 & & 79 & 66 & 51 & \\
\hline
\end{tabular}

Table 2: Comparison of overall mean score of the modified ATHCTS between 1st- and 3rd-year students

\begin{tabular}{|c|c|c|c|}
\hline & Mean & SD & p value \\
\hline 1st-year & 3.61 & 1.246 & 0 \\
\hline 3rd-year & 3.97 & 1.101 & \\
\hline
\end{tabular}

\section{Exploratory factor analysis}

Table 3: Varimax rotation with two factors for responding sample ${ }^{\mathrm{a}}$.

\begin{tabular}{|c|c|c|c|}
\hline \multirow{3}{*}{ Item } & \multirow{3}{*}{ Label } & \multicolumn{2}{|c|}{ Factor loading } \\
\hline & & I & II \\
\hline & & $\alpha=0.907$ & $(\alpha=0.493)$ \\
\hline 8 & $\begin{array}{l}\text { The interprofessional approach } \\
\text { improves the quality of care to } \\
\text { patients/clients. }\end{array}$ & 0.826 & -0.11 \\
\hline 12 & $\begin{array}{l}\text { Having to report observations to a } \\
\text { team helps team members better } \\
\text { understand the work of other } \\
\text { health professionals. }\end{array}$ & 0.799 & 0.112 \\
\hline 7 & $\begin{array}{l}\text { Working in an interprofessional } \\
\text { environment keeps most health } \\
\text { professionals enthusiastic and } \\
\text { interested in their jobs }\end{array}$ & 0.771 & -0.004 \\
\hline 14 & $\begin{array}{l}\text { Team meeting foster } \\
\text { communication among members } \\
\text { from different professions or } \\
\text { disciplines. }\end{array}$ & 0.739 & -0.031 \\
\hline 4 & $\begin{array}{l}\text { The interprofessional approach } \\
\text { makes the delivery of care more } \\
\text { efficient. }\end{array}$ & 0.702 & -0.142 \\
\hline 13 & $\begin{array}{l}\text { Hospital patients who receive } \\
\text { interprofessional team care are } \\
\text { better prepared for discharge than } \\
\text { other patients. }\end{array}$ & 0.692 & -0.136 \\
\hline 3 & $\begin{array}{l}\text { The give and take among team } \\
\text { members helps them make better } \\
\text { patient/client care decisions. }\end{array}$ & 0.672 & -0.027 \\
\hline 11 & $\begin{array}{l}\text { The interprofessional approach } \\
\text { permits health professionals to } \\
\text { meet the needs of family caregivers } \\
\text { as well as patients. }\end{array}$ & 0.668 & -0.017 \\
\hline 10 & $\begin{array}{l}\text { Health professionals working } \\
\text { as team are more responsive } \\
\text { than others to the emotional and } \\
\text { financial needs of patients/clients. }\end{array}$ & 0.612 & -0.231 \\
\hline 1 & $\begin{array}{l}\text { Patients/clients receiving } \\
\text { interprofessional care are more } \\
\text { likely than others to be treated as } \\
\text { whole persons }\end{array}$ & 0.53 & -0.137 \\
\hline
\end{tabular}

\begin{tabular}{|c|c|c|c|}
\hline 5 & $\begin{array}{c}\text { Developing a patient/client care } \\
\text { plan with other team members } \\
\text { avoids errors in delivering care }\end{array}$ & 0.517 & -0.118 \\
\hline 6 & $\begin{array}{c}\text { Working in an interprofessional } \\
\text { manner unnecessarily complicates } \\
\text { things most of the timeb }\end{array}$ & 0.153 & 0.697 \\
\hline 2 & $\begin{array}{c}\text { Developing an interprofessional } \\
\text { patient/client care plan is } \\
\text { excessively time-consumingb }\end{array}$ & -0.082 & 0.429 \\
\hline 9 & $\begin{array}{c}\text { In most instances, the time } \\
\text { required for interprofessional } \\
\text { consultations could be better spent } \\
\text { in other waysb }\end{array}$ & -0.333 & 0.42 \\
\hline
\end{tabular}

aModified ATHCTS (Curran et al, 2007) was used as the instrument.

${ }^{\mathrm{b}}$ Negatively worded items were reverse-scored to calculate

The Kaiser-Meyer-Olkin index was 0.911, indicating sampling adequacy, and the Bartlett Sphericity Chi Square index was 1269.5 $(\mathrm{p}<0.001)$, convincingly rejecting the null hypothesis that the correlation matrix was an identity matrix and thus unsuitable for factor analysis. Cronbach's alpha of the 14-item modified ATHCTS was 0.819 , revealing a high rate of internal consistency. The modified ATHCTS questionnaire was categorized into the following two subscales: "Quality of care" and "Team efficiency" with Cronbach alpha measures of 0.907 and 0.493 , respectively (Table 3).

\section{Regression factor scores}

As shown in Figure 1, in only one out of the three subscales, "Quality of care", the regression factor score of 3rd-year students was significantly higher than that of 1st-year students ( $0.301 \pm 0.699$ vs. $-0.255 \pm 1.072, \mathrm{p}<0.001)$ (Figure 1 ).

\section{Discussion}

The present results showed that the overall mean score in 3rd-year students were significantly higher than that in 1st-year students at MNUMS. Since this study was a cross-sectional study but not a longitudinal study, the population was different. However, both students took the same curricula without an IPE program. On the other hand, factor analysis revealed two factors in the modified ATHCTS used here. Interestingly, the regression factor score of "Quality of care" in 3rd-year students was significantly higher than that in 1st-year students. The overall mean score in 3rd-year students were significantly higher than that in 1st-year students at MNUMS on the modified ATHCTS. The results showed First year students did not respond positively to the MPE While these IPE initiatives can add value to a safe and effective workforce they will 


\section{Global Journal of Reproductive Medicine}

only reach their potential when parallel changes to improve the inter professional culture occur in health care and health education settings. This represents perhaps the greatest challenge for the future of IPE, and one which will require collaborative effort from the health workforce at individual, organizational, and structural levels. In terms IPE evaluation, the findings also highlight the importance of measuring baseline attitudinal constructs as part of systematic evaluate activities when introducing new IPE initiatives within academic settings [13].

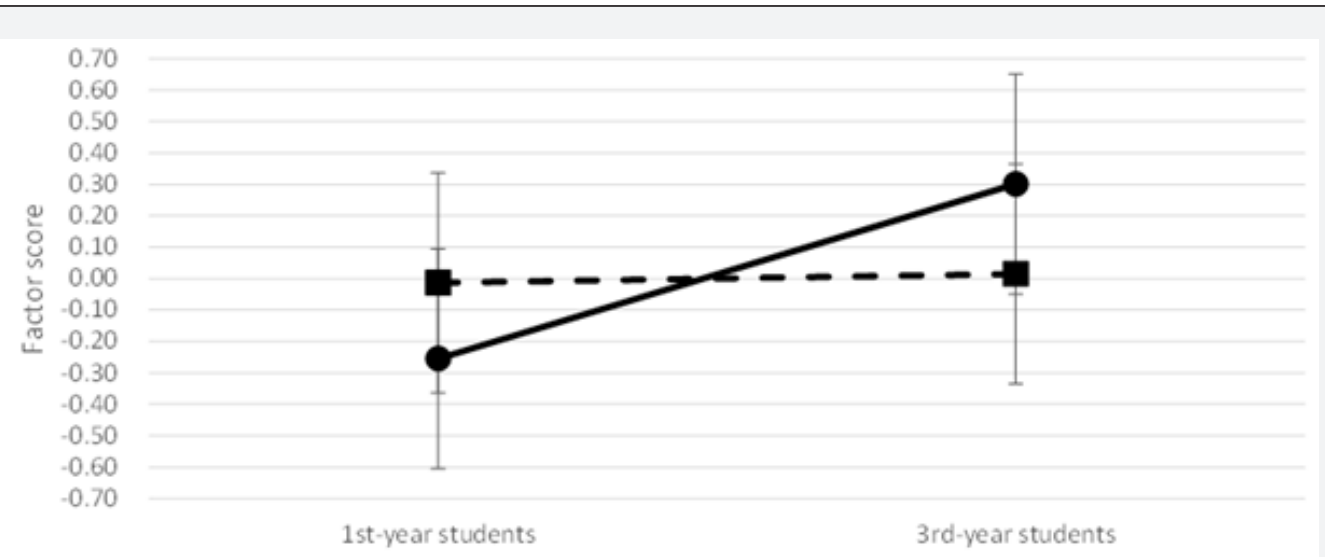

Figure 1: Comparison of regression factor score of the modified ATHCTS between 1st and 3rd year students. Regression factor scores of "Quality of care" (circle) and "Team efficacy" (square) subscale of the modified ATHCTS. Bars indicate standard error. Asterisk indicates significant difference between 1 st- and 3rd-year students score with $p$ value $<0.05$, according to the Mann-Whitney test.

Comparison on curriculum contents of participants showed that fundamentals of PBL are taught only for PT and OT as an independent training and this revealed a need to involve it to the curriculum for all other professional classes. Apart from the curriculum for preparing hospital specialists at the School of Nursing MNUMS, the innovation of other curriculum for preparing hospital specialists that are being implemented at the other branch schools is an urgent issue for researchers and cooperation of Deans of branch schools, Vice president of Training and Division of Training and Management can be vital to solve this issue. Otherwise, conducting IPE for structure of nurturing hospital specialists as well as at the Mongolian National University of Mongolia is vital now. According to the guideline of WHO, it is important to develop basic training programs of IPE designed for Mongolian specifics. Incorporating IPE programs on fundamental and specialized trainings will prepare highly potentiated graduates who can provide a qualified hospital care and this incorporation is important both for educational intuitions and hospital care system.

No teaching hospital status in Mongolia yet and so the first university affiliated training hospital in 2018 is going to create opportunities for IPE implementation. The results showed that 3rdstudents possessed more positive attitudes toward IPE than 1st year students of MNUMS, suggesting that exposure to clinical practice may result in withdrawal of the attitudes toward healthcare teams. Only the regression factor score of "team efficacy" out of three factors in the modified ATHCTS obtained by factor analysis was significantly negatively inclined in alumni as compared with undergraduate students. This indicates same results with study of Takatoshi Makino, et al. [11]. In two scales of "quality of team care" and "team efficiency", there was no difference in the ATHCTS between 3rd year students and 1st year students. This may be supported by the finding that undergraduate respondents with high ATHCTS score felt that the team approach improves the quality of care to patients as trainees learn teamwork skills and how to work with the professionals on the team. To make IPE more effective consideration should be given to multiple exposures and the different demands of the health science curriculum.

Factor 2 highlights recognition of improved future professional practice based on effective teamwork and mutual respect. It helps students to develop an understanding of the resources and networks required in healthcare, promotes positive views of other health professionals and enhance professional practice. this study is an attempt to provide some evidence in support IPL through the development of an evaluation tool to measure the effectiveness of the implementation of an innovative model of IPE for undergraduate health science students. Given global trends in this direction, it is vital that IPE be introduced in our medical and allied health sciences curricula. Considering the multi professional nature of health care delivery, it is crucial that IPE activities be created where students in all health professions learn with, about and from each other. A future article on this subject will focus on practical suggestions as to how IPE activities might be implemented.

It related to the 3rd grade students' involvements of the hospital practice and their wide range of understanding of hospital care. For professional fundamental and specialized trainings' seminars, the students report results by team work and practices are held in hospital as students are part of hospital team and are cooperated medical specialists reveal its efficiency for professional skills development. Although in Mongolia, each hospital specialists are prepared by traditional methods, it is crucial to implement IPE to nurture highly qualified specialists 


\section{Global Journal of Reproductive Medicine}

at the level of social demands. Comparison study on nursing curriculum contents of Mongolia and Gunma university of Japan showed that 1st course students study general education subjects by system of grade in Mongolia, while subjects of "Principles of Collaborative Health Care" and in 3rd course "Practicum of Collaborative Health care" are taught In Gunma University and those are illustrating systematic differences. The regression factor score of "Quality of care" in 3rd-year students was significantly higher than that in 1st-year students.

In this study, participants identified personal, rather than systemic, factors as being more important in causing inter professional conflict. This suggests that strengthening IPE educational programs could be as effective in resolving inter professional conflicts as improving hospital collaboration systems. There is a need to provide information about the work of other health professions in the IPE curriculum (6) in order to correct stereotypes and encourage positive attitudes toward all professions (7). The overall mean score in 3rd-year students were significantly higher than that in 1st-year students. The factor of "Quality of care" in 3rd-year students are significantly higher than that in 1st-year students. However factor of "Team efficiency" in 3rd-year students are not significantly higher than that in 1st-year students. In order to expand IPE opportunities, an appropriate educational system, and a curriculum will need to be developed.

As an important method of breaking down intellectual and cultural barriers between different health professionals, IPE may help to convert the traditional organizational structure into an integrative, cooperative system, helping to improve patient outcomes. Two subscales were obtained from the factor analysis of the modified ATHCTS. As shown in Table III, the fundamental structure of the two factors the same as those reported previously. It is therefore conceivable that the 14-item modified version might be better to assess the attitudes toward health care teams from viewpoints of universal usage among multiple health professions and the students.

\section{Limitations}

This was a first step to clarify the present state of IPE in the Mongolia. Further surveys targeting nursing or other health professions should be done in the future.

\section{Conclusion}

The conclusion of the study results revealed that if the "Principles of Collaborative health Care" and "Practicum of Collaborative Health care" were incorporated to the undergraduate training curriculum for implementing the IPE in the system of professional institutions and health care organizations in Mongolia, it would be the most important for students' mutual learning and to prepare qualified hospital specialists who meet social demands. Therefore, there is a need for more detailed studies using the chance of students' positive attitude to the successful implementation of this program.
The present results showed that students possessed more positive attitudes toward IPE than 3rd year students, suggesting that exposure to clinical practice may result in withdrawal of the attitudes toward healthcare teams. Only the regression factor score of "team value" out of two factors in the modified ATHCTS obtained by factor analysis was significantly negatively inclined in 3rd year students as compared with 1st year students. These results suggest that the withdrawal of the attitudes toward healthcare teams in the clinical practice experience may be related to "team value". In service IPE may play role in sustaining attitudes and providing a useful CP, which results in good clinical outcome.

The present results showed that students possessed more positive attitudes toward IPE than 3rd year students, suggesting that exposure to clinical practice may result in withdrawal of the attitudes toward healthcare teams. Only the regression factor score of "team value" out of two factors in the modified ATHCTS obtained by factor analysis was significantly negatively inclined in 3rd year students as compared with 1 st year students. These results suggest that the withdrawal of the attitudes toward healthcare teams in the clinical practice experience may be related to "team value". In service IPE may play role in sustaining attitudes and providing a useful $\mathrm{CP}$, which results in good clinical outcome.

\section{Acknowledgement}

This work was supported in part by Grant-in-Aid for Scientific Research (C) $15 \mathrm{~K} 08541$ (H.S.) and Grant-in-Aid for Scientific Research (B) 15 H0 4749 (H.W.) from Ministry of Education, Culture, Sports, Science and Technology of the Japanese Government and Gunma University Initiative for Advanced Research (GAIR). We also thank Visiting Professor Takako Yasukawa for her valuable support. We also thank Mr. Akihiro Yuasa, Mr. Dai Yamamura, Ms. Miho Matsumoto and Ms. Yasuko Abe for their kind assistance.

\section{Declaration of interest}

The authors report no declarations of interest.

\section{References}

1. Heinemann GD, Schmitt MH, Farrell MP, Brallier SA (1999) Development of an Attitudes Toward Health Care Teams Scale. Eval Health Prof 22(1): 123-142.

2. Curran VR, Sharpe D, Forristall J (2007) Attitudes of health sciences faculty members towards interprofessional teamwork and education. Med Educ 41(9): 892-896.

3. Nakazawa R., Sakamoto M, Oidov B (2012) Physical Therapy Education in Mongolia -Students' Responses to a Questionnaire Survey about Rehabilitation and Physical Therapy. Physical Therapy Education in Mongolia 24: 605-608.

4. Lumague M, Morgan A, Mak D, Hanna M, Kwong J, et al. (2006) Interprofessional education: the student perspective. J Interprof Care 20(3): 246-253.

5. (2001) Crossing the Quality Chasm: a new health system for the 21st century. Institute of Medicine (US) Committee on Quality of Health Care in America Washington DC: National Academy Press.

6. World Health Organization (2013) Transforming and scaling up health professionals' Education and Training. World Health Organization. 
7. Brashers V, Peterson C, Tullmann, D, Schmitt M (2012) The University of Virginia interprofessional education initiative: an approach to integrating competencies into medical and nursing education. J Interprof Care 26(1): 73-75.

8. Breitbach AP, Sargeant DM, Gettemeier PR., Ruebling I, Carlson J, et al. (2013) From buy-in to integration: melding an interprofessional initiative into academic programs in the health professions. J Allied Health 42(3): e67-73.

9. Barker K, Oandasan I (2005) Interprofessional care review with medical residents: lessons learned, tensions aired-a pilot study. J Interprof Care 19(3): 207-214.

10. Hayashi T, Shinozaki H, Makino T, Ogawara H, Asakawa Y, et al. (2012) Changes in attitudes toward interprofessional health care teams

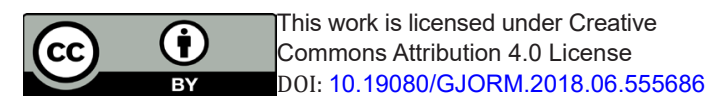

and education in the first- and third-year undergraduate students. Interprof Care 26(2): 100-107.

11. Makino T, Shinozaki H, Hayashi K, Lee B, Matsui H, et al. (2013) Attitudes toward interprofessional healthcare teams: a comparison between undergraduate students and alumni. J Interprof Care 27(3): 261-268.

12. DiStefano C, Zhu M, Mindrila D (2009) Understanding and using factor scores: Considerations for the applied researcher. Practical Assessment, Research \& Evaluation 14(20): 892-896.

13. Hyer K, Fairchild S, Abraham I, Mezey M, Fulmer T (2009) Measuring attitudes related to interdisciplinary training: revisiting the Heinemann, Schmitt and Farrell attitudes toward health care teams scale. J Interprof Care 14(3): 249-258.

Your next submission with Juniper Publishers will reach you the below assets

- Quality Editorial service

- Swift Peer Review

- Reprints availability

- E-prints Service

- Manuscript Podcast for convenient understanding

- Global attainment for your research

- Manuscript accessibility in different formats

( Pdf, E-pub, Full Text, Audio)

- Unceasing customer service

Track the below URL for one-step submission https://juniperpublishers.com/online-submission.php 